\title{
Countercurrent gas-liquid flow in plate-fin heat exchangers with plain and perforated fins
}

\author{
N. Souidi ${ }^{\mathrm{a}}$, A. Bontemps ${ }^{\mathrm{b}, *}$ \\ ${ }^{a}$ GRETh-CEA Grenoble, 17 rue des Martyrs, F-38054, Grenoble Cedex 9, France \\ ${ }^{\mathrm{b}}$ LEGI-GRETh, Université Joseph Fourier, 17 rue des Martyrs, F-38054 Grenoble Cedex 9, France
}

\begin{abstract}
Countercurrent gas-liquid flow in narrow rectangular channels simulated by plain and perforated fins is studied. Different flow patterns dependent on flow rates are observed and visualised in the channels. Flooding velocities and pressure drops are measured. Results are compared with previous experimental data obtained in rectangular channels. The present results focus on two particular types of flooding phenomena: that occurring at the column base and linked to plugging and that at the top, linked to reentrainment. A further set of experiments using perforated fins surprisingly shows a greater tendency to flooding of the perforated fins. However, there are marked differences for the two types of fins and an explanation may be the two distinct flooding occurrences.
\end{abstract}

Keywords: Flooding; Narrow rectangular channels; Countercurrent flow; Plain fins; Perforated fins; Compact heat exchangers; Reflux condensation

\section{Introduction}

In vertical gas-liquid countercurrent flow at constant liquid flow rate increasing the gas flow rate will eventually lead to a critical point at which upward flow of some liquid is observed. This occurrence is referred to as flooding.

More precisely, flooding may be defined by a series of phases (Delhaye, 1981):

(a) For low gas flow rates, liquid (L) flows downwards unaffected by the upward flow of the gas (G) (Fig. 1(a)).

(b) As the gas flow rate increases, waves of large amplitude travelling upward appear along the film (Fig. 1(b)).

(c) Raising the gas flow rate more causes the film to become 'agitated' and droplets are torn off from the crests of the waves and entrained with the gas flow (Fig. 1(c)).

(d) Gas flow rates above this lead to more and more liquid being entrained (Fig. 1(d)).

(e) Eventually wall drying will occur as well as an upward liquid film flow (Fig. 1(e)).

The third stage (c) is particularly interesting and corresponds to the so-called flooding point. However, definition of this transition varies among authors since it seems to be greatly dependent on the experimental system. Some authors define the flooding point via entrainment levels and others on liquid bridging of the flow channel. Flooding can

${ }^{*}$ Corresponding author. either be considered as a result of the gas-liquid interface instability or as a limit condition of the countercurrent flow.

Flooding limits can be determined either from visual observations or from experimental measurements:

(a) Typical visual observations and different models associated are the occurrence of a standing wave on the liquid film (Shearer and Davidson, 1965); liquid film instabilities (Jameson and Cetinbudaklar, 1969; Cetinbudaklar and Jameson, 1969; Imura et al., 1977); no net flow in the liquid film (Grolmes et al., 1974); droplet entrainment from the liquid film (Dukler and Smith, 1977).

(b) Flooding limit consequences can be detected by measurement (Bachir, 1987): the occurrence of a standing wave on the liquid film (film thickness measurement); droplet entrainment from the liquid film (pressure drop or flow rate measurement).

However, only a quantitative definition of flooding emerges from previous studies (Delhaye, 1981): pressure drop increases sharply above the injection zone indicating that droplets are entrained with the gas flow.

Generally, it seems that there is flooding when interfacial friction balances buoyancy and inertial forces. However, flooding also depends on various experimental parameters such as:

(i) Entrance or exit conditions for the liquid: an abrupt entry causes local perturbations and is favourable to flooding (Barathan and Wallis, 1983; Mishima and Nishihara, 1984). 


\section{Notation}

$a, b \quad$ dimensions of channels [m]

Bo Bond number (Eq. (6)) [-]

$D_{\mathrm{h}} \quad$ hydraulic diameter (Eq. (2)) [m]

$\mathrm{Fr} \quad$ specific Froude number (Eq. (11)) [-]

$g \quad$ acceleration due to gravity $\left[\mathrm{m} \mathrm{s}^{-2}\right]$

$J \quad$ superficial velocity $\left[\mathrm{m} \mathrm{s}^{-1}\right.$ ]

$J^{*} \quad$ dimensionless superficial velocity [-]

$K u \quad$ Kutateladze number (Eq. (5)) [-]

$\dot{M} \quad$ mass flow rate $\left[\mathrm{kg} \mathrm{s}^{-1}\right]$

$n$ number of channels [-]

$P \quad$ pressure [bar]
$Q \quad$ volume flow rate $\left[\mathrm{m}^{3} \mathrm{~s}^{-1}\right]$

$\dot{Q} \quad$ volume flow rate per unit wetted perimeter $\left[\mathrm{m}^{2} \mathrm{~s}^{-1}\right]$

Re specific Reynolds number (Eq. (1)) [-]

$S$ area $\left[\mathrm{m}^{2}\right]$

$\mu \quad$ dynamic viscosity [Pa s]

$\rho \quad$ mass density $\left[\mathrm{kg} \mathrm{m}^{-3}\right]$

$\sigma \quad$ surface tension $\left[\mathrm{N} \mathrm{m}^{-1}\right]$

Subscripts

G gas

$i \quad i$ th phase, gas or liquid

$\mathrm{L} \quad$ liquid

$\mathrm{S} \quad$ superficial

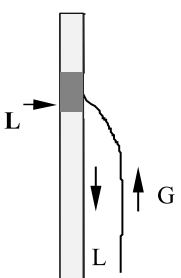

(a)

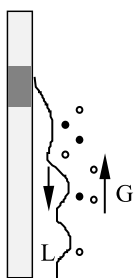

(b)

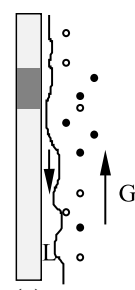

(c)

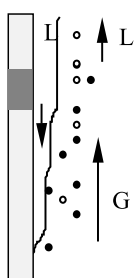

(d)

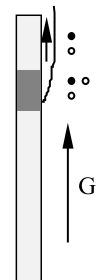

(e)
Fig. 1. The onset and evolution of flooding, L (liquid), G (Gas), (a) countercurrent flow and no entrainment, (b) wavy flow and droplets entrainment, (c) agitated flow and droplets entrainment, (d) liquid film entrainment, (e) upward liquid flow.

(ii) Channel diameter: it is well established that proximity of the walls tends to favour the onset of flooding, (Bachir, 1987). (iii) Long tube lengths: long lengths in circular geometry are favourable to the onset of flooding but these effects are masked for high viscosity liquid. In rectangular channels, a study by Celata et al. (1986) showed no length effect. It may be that length effects are observed by entrance and exit conditions as flooding is generated by local perturbations linked to these conditions.

(iv) Physical properties of the fluid: high liquid viscosity seems to diminish the tendency to flooding and high surface tension also has a stabilising effect especially in narrow channels (Damon, 1996). However, no clear influence has been established.

Flooding in countercurrent gas-liquid flows is a significant problem in the process industry, particularly in reflux condensers where vapour flows upward and the condensate falls down countercurrent to it. Flooding induces an undesirable removal of liquid and this may lead to blockage of the condenser. As a consequence, flooding has been the subject of several experimental investigations in circular tubes for the last five decades. No adequate theories have been provided so far. Some empirical correlations have been developed but they can only be used within a limited range of validity. This range depends on geometry, gas and liquid flow rates and experimental setup. The current use of compact heat exchangers as reflux condensers cannot neglect a phenomenon like flooding. A vapour-gas mixture is introduced at the lower part of the condenser and the reflux liquid flows downwards enriched with the less volatile components. Such a device is designed for separating these less volatile species from gas mixtures. With this geometry, it is essential that the gas flow rate is not so high as to cause flooding. However, the lack of reliable correlations for predicting the onset of flooding in the reflux condensation case remains a substantial problem (Webb, 1996).
The aim of the present study is to reproduce flooding conditions in a simulated reflux condenser. When used to compare the data, all the experiments are carried out for a fixed gas flow rate under adiabatic conditions. The test section is similar to a compact heat exchanger but air and water replace vapour and condensate, respectively. Water is injected through a porous system. The effect of high and low flow rates on flow configurations and on flooding limits is examined. Perforated fins are also studied since they are employed in the process industry for condensation and they are considered to be more efficient in terms of heat transfer. However, their efficiency in terms of flooding has never been established. Pressure drop measurements at the bottom of the test section are used to characterise the flooding limit accurately. Finally, comparisons with previous studies in rectangular channels are made as well as with previously published correlations.

In this study, only the hydraulic aspects are simulated in order to characterise the flow in narrow rectangular channels. Compared to the study of a compact heat exchanger functioning in reflux condensation, there is an evident difference in the liquid injection system. Indeed, in the case of reflux condensation, the condensate is formed gradually and the film thickness is not constant throughout the condenser. Injecting the liquid at the top can influence the flooding phenomenon. The common points between the hydraulic study and the thermal study are the injection of gas at the lower end, the geometry considered, the countercurrent flow obtained and the characterisation of the flooding point by the influence of the vapour flow on the liquid flow. Additionally, the adiabatic system stabilises quickly and the flow rates are easily adjusted to measure the flooding points.

\section{Experiment}

Fig. 2 is a schematic view of the air-water experimental facility. Such an equipment is designed to visualise the flow and to measure gas and liquid flow rates. Additionally, the experimental setup allows pressure drop measurements.

The water is injected through a porous system in the upper part of the test section. The porous system evenly distributes the water into every channel. Liquid flows down due to gravity and it is collected at the bottom of the experiment to be reinjected in the system. No additional device is used to collect liquid flow except gravity. The liquid flow rate is measured by two calibrated flowmeters for two different ranges $10-50$ or $31.5-300 \mathrm{l} / \mathrm{h}$

Ambient air is blown at the lower part of the test section and enters the test section at $70^{\circ} \mathrm{C}$. A convergent system supplies the air flow to the channels. The flow rate is regulated by 


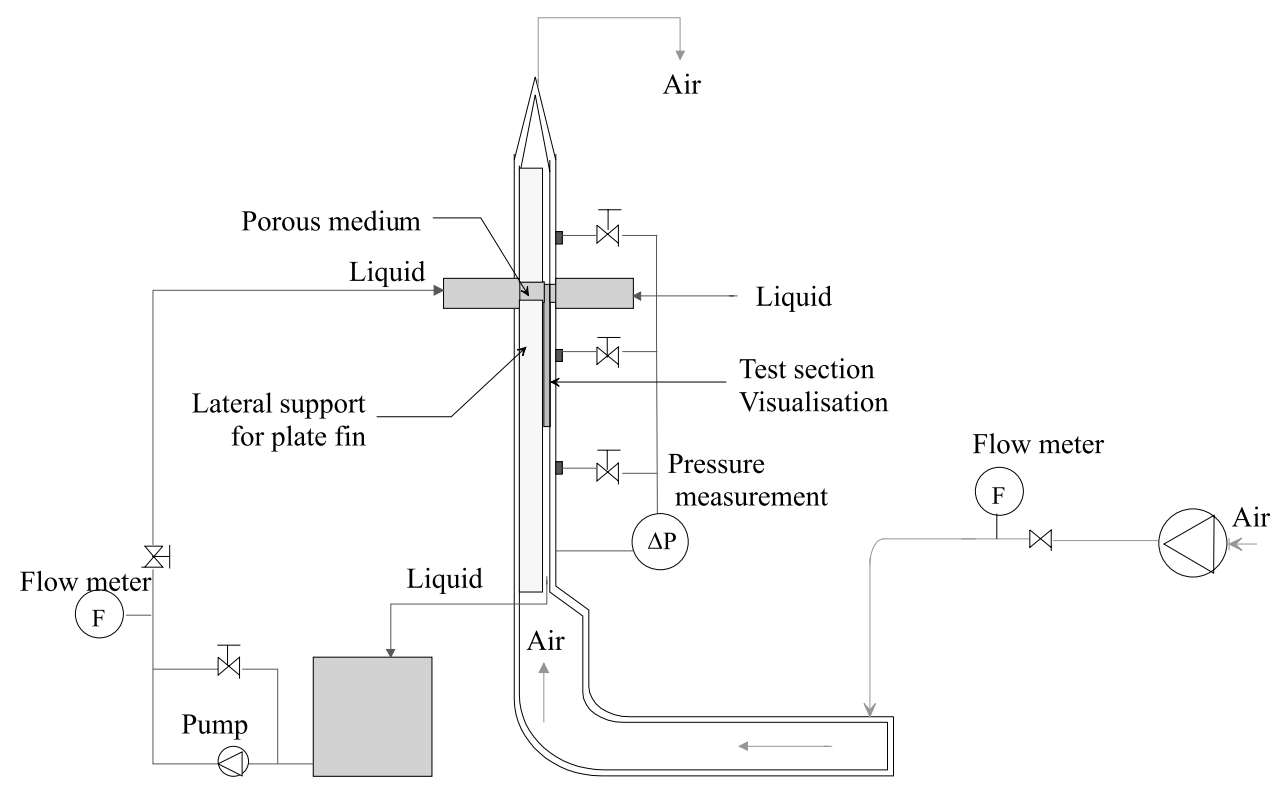

Fig. 2. Diagram of the experimental facility.

two valves and measured by a calibrated flowmeter in the range $0.2-6 \mathrm{~m}^{3} / \mathrm{h}$.

\subsection{Estimation of the uncertainty on the mass flowmeter}

The uncertainty on the mass flowmeter data by the calibration certificate of the manufacturer is of $\pm 1 \%$ of the maximum flow which is $6 \mathrm{~m}^{3} / \mathrm{h}$. We thus have a $0.06 \mathrm{~m}^{3} / \mathrm{h}$ absolute error.

\subsection{Estimation of the uncertainties on the rotameters}

For the range of flow $[10-50 \mathrm{l} / \mathrm{h}]$, the misreading is estimated at $\pm 0.5 \mathrm{l} / \mathrm{h}$. For the range of flow [31.5-300 $\mathrm{l} / \mathrm{h}]$, the misreading is estimated at $\pm 2.5 \mathrm{l} / \mathrm{h}$.

\subsection{Uncertainty on the determination of the flooding air flow rate}

The flooding point is evaluated according to the measurement of the pressure together with visual observations. However, while the measurements were taken, it was that there is an uncertainty on the determination of the flooding air flow rate, uncertainty estimated at $\pm 0.1 \mathrm{~m}^{3} / \mathrm{h}$, which gives a total uncertainty of $0.16 \mathrm{~m}^{3} / \mathrm{h}$.

The test section consists of an aluminium corrugated plate $0.4 \mathrm{~mm}$ thick sandwiched between two parallel plane plates resulting in 56 rectangular channels, see Fig. 3. The channel dimensions are $2.14 \times 5.10 \mathrm{~mm}^{2}, a \times b$ cross-section. Plain and perforated fins are used. The front plate is made of Plexiglas to visualise the flow patterns in the channels.

Pressure measurements are located at the top, the middle and the bottom of the test section and the pressure drop between the inside test section and atmospheric pressure is measured. The top test section is opened to the atmosphere. As a consequence, pressure measurement located at the top gives the atmospheric pressure and the one located at the middle does not present a significative difference of pressure. The pressure drop between the bottom of the test section and atmospheric pressure is measured by using a manometer graduated from 0 to $120 \mathrm{~mm}$. The overall system is adiabatic at atmospheric pressure.
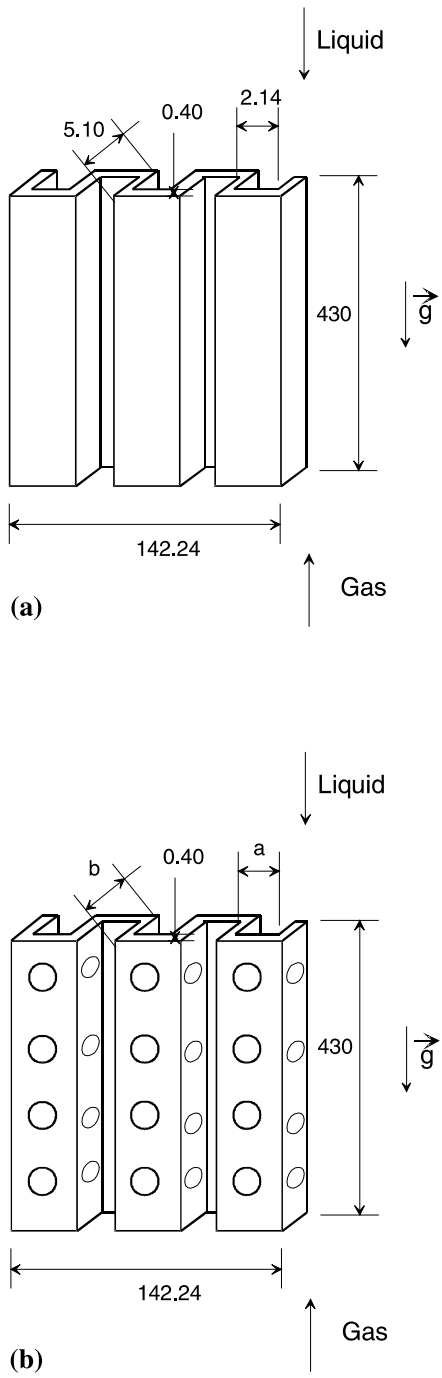

Fig. 3. Characteristics of the fin plate (dimensions in $\mathrm{mm}$ ), (a) plain fins, (b) perforated fins. 


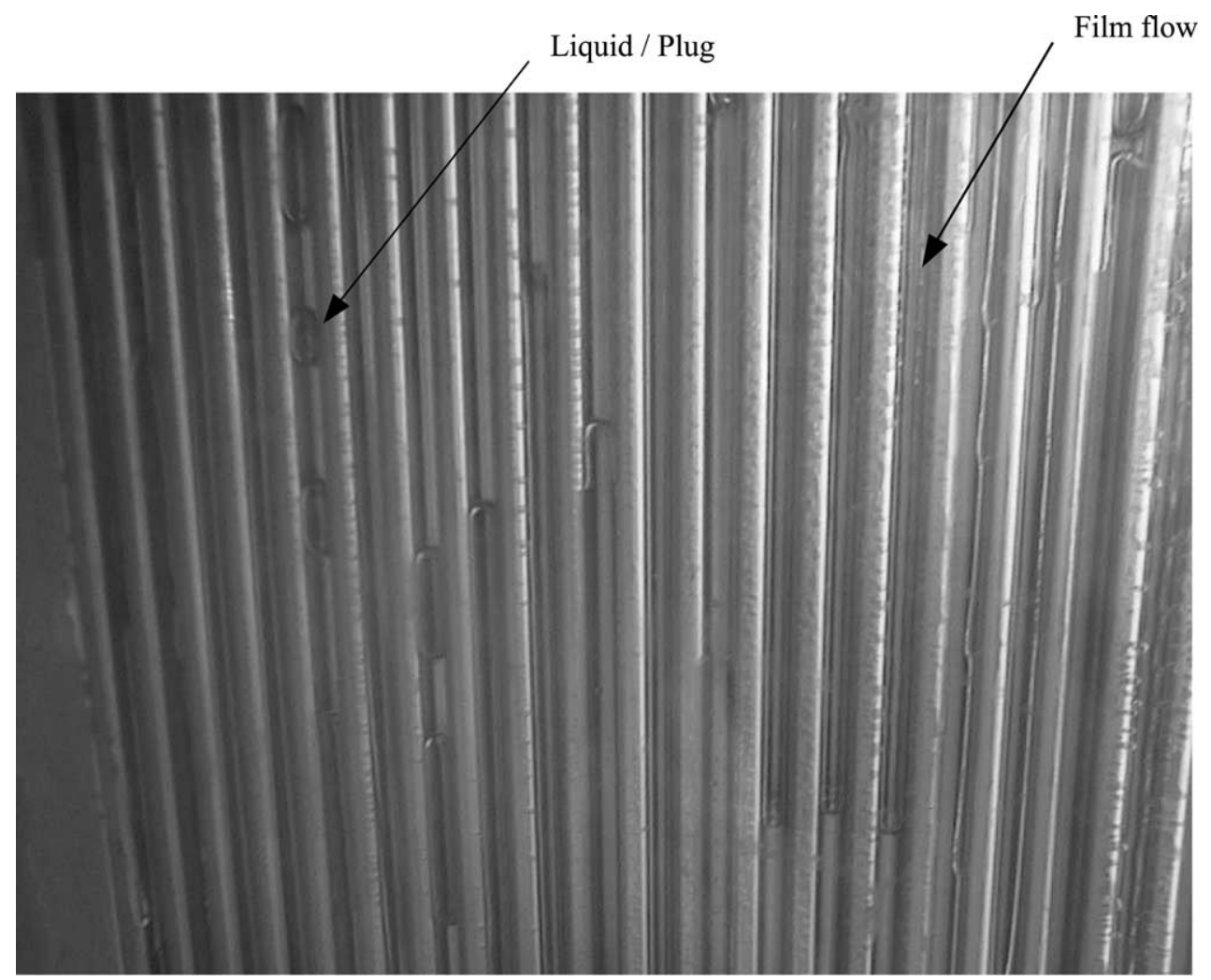

Fig. 4. View of the plate fin flow patterns.

The liquid Reynolds numbers vary from 6 to 350. The Reynolds numbers in terms of superficial velocities for both phases are:

$R e_{\mathrm{si}}=\frac{\rho_{i} J_{i} D_{\mathrm{h}}}{\mu_{i}}, \quad i=\mathrm{G}$ or $\mathrm{L}$

where $D_{\mathrm{h}}$ is the hydraulic diameter, $D_{\mathrm{h}}=\frac{2 a b}{(a+b)}$.

Since the test section is made of transparent walls, observation of 28 channels and photography of flow patterns during measurement are possible (Fig. 4).

\section{Experimental results and discussion}

\subsection{Visual observations and pressure drop measurement of plain fins}

In a vertical countercurrent flow, the flow patterns observed depend on gas and liquid flow rates, dimensions of the channel and physical properties of the gas-liquid system such as viscosity or surface tension. Typical flow patterns of countercurrent flow observed in the test section are shown in Fig. 5: film flow, plug and churn flows. All these patterns are observed simultaneously in different channels. However, some configurations preferentially appear for a specific range of liquid flow rates: churn and film flow occur at high liquid flow rates (100$300 \mathrm{l} / \mathrm{h}$ ) with thick film flow predominating. Thin film, churn and plug flow appear for low liquid flow rates $(10-100 \mathrm{l} / \mathrm{h})$ with plug flow predominating in this case.

The classification of these flows was based on: film flow where downward flowing liquid fills a significant part of the channel (Fig. 5(a)); plug flow where liquid plugs flow down and gas goes through passages separating the liquid plugs (Fig. 5(b)); and churn flow where liquid plugs tend to increase in size and proximity (Fig. 5(c)). Again, well-defined transition between these flow patterns is difficult to fix over such a large number of channels. A resulting difficulty is to determine the onset of flooding in the test section since some channels quickly reach a flooded state whereas others retain a countercurrent flow configuration.

A measurable characteristic of flooding is a sharp increase in pressure drop above the injection zone. Since the pressure measurement above the injection zone was not measurable the flooding limit was determined by measuring the pressure drop between the inlet and the outlet of the test section.

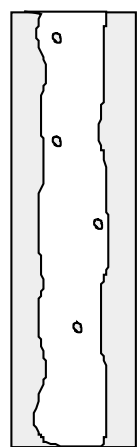

(a)

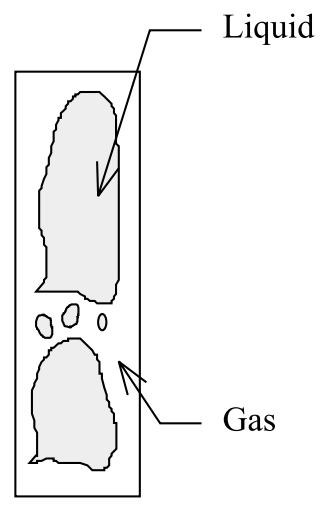

(b)

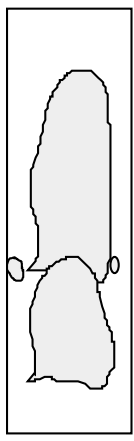

(c)
Fig. 5. Flow patterns observed in the present vertical countercurrent flow, (a) film flow, (b) plug flow, (c) churn flow. 


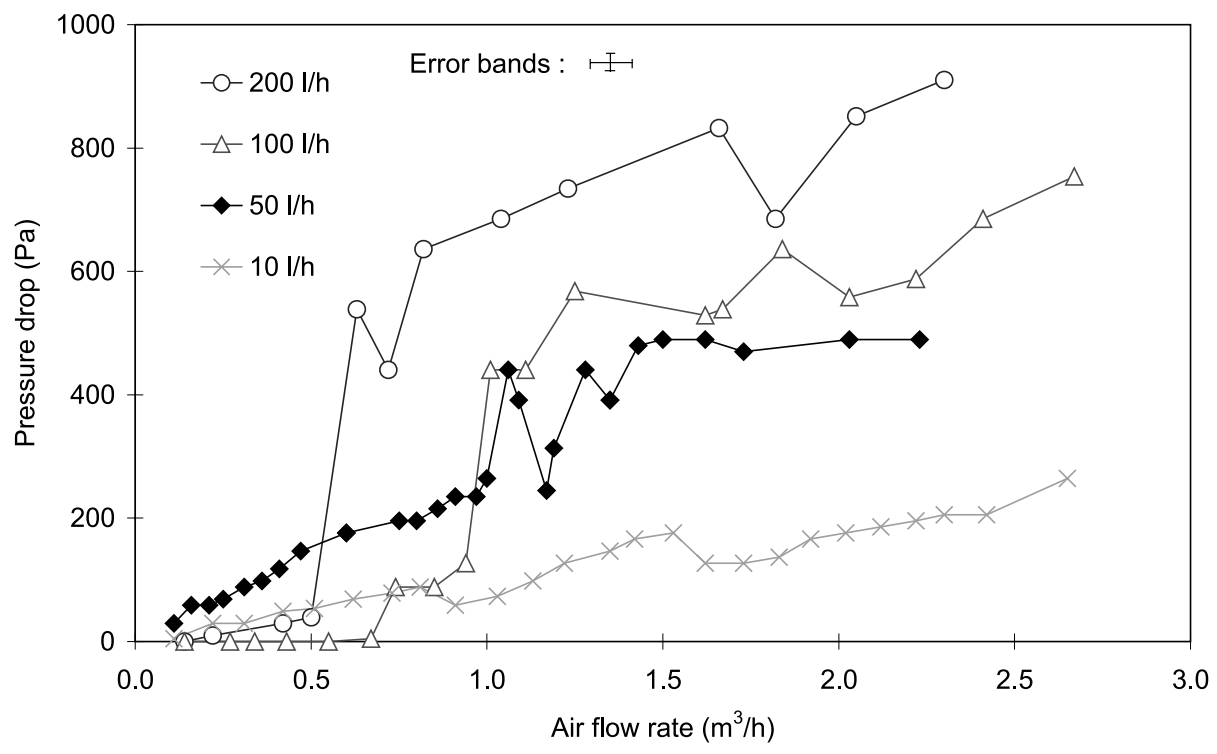

Fig. 6. Pressure drop evolution with gas-liquid flow rate.

For four liquid flow rates [10, 50, 100, 200 1/h], see Fig. 6, an increase of pressure drop at the flooding point is observed. Then, the pressure increases more or less irregularly with the liquid flow rate. It is necessary to identify two causes of pressure drop augmentation at flooding: surface friction forces and droplets in the gas core. Below the injection liquid zone the pressure drop increase is caused by surface friction forces since the liquid film is thicker there. Above this zone, pressure drop alteration is caused by droplet entrainment by the gas phase. This second zone is more inclined to flooding. However, pressure drops measured in the present study are defined as the difference between pressure at the bottom of the test section and atmospheric pressure outside. Thus, pressure drop measurements were only possible at the lower part of the test rig since measurements taken higher do not present a sufficient difference with external pressure.

Therefore, the two methods, visual observations and pressure drop measurement, allow the determination of the flooding limit.

\subsection{Flooding characteristics}

It is difficult to define precisely the flooding point in a multichannel exchanger as one can do for a single channel since the phenomenon is unstable and it does not occur simultaneously in all the channels. It occurs also differently for the two flow rate ranges considered here.

At high liquid flow rates in the range $100-3001 / \mathrm{h}$, the liquid cannot flow down the channels and some droplets are entrained up to the top of the test section. Then, as the gas flow rate increases, more and more liquid is entrained and tends to remain at the upper end of the test section (Fig. 7). In this range, we consider the test section to be flooded when some droplets are carried out of the test section.

At lower liquid flow rates $(10-100 \mathrm{l} / \mathrm{h})$, flooding is caused by the instability of the liquid in the lower part of the test section. The liquid is removed from the lower part to the top of the test section and the gas-liquid flow becomes cocurrent for a few seconds. The liquid flow tends to oscillate between co- and countercurrent regimes. This type of flooding will occur in a small number of channels. The instability of the liquid film tends to spread to other channels and then to every channel of the test section particularly when the gas flow rate increases. So, we consider the test section to be flooded when the liquid flow oscillates in a
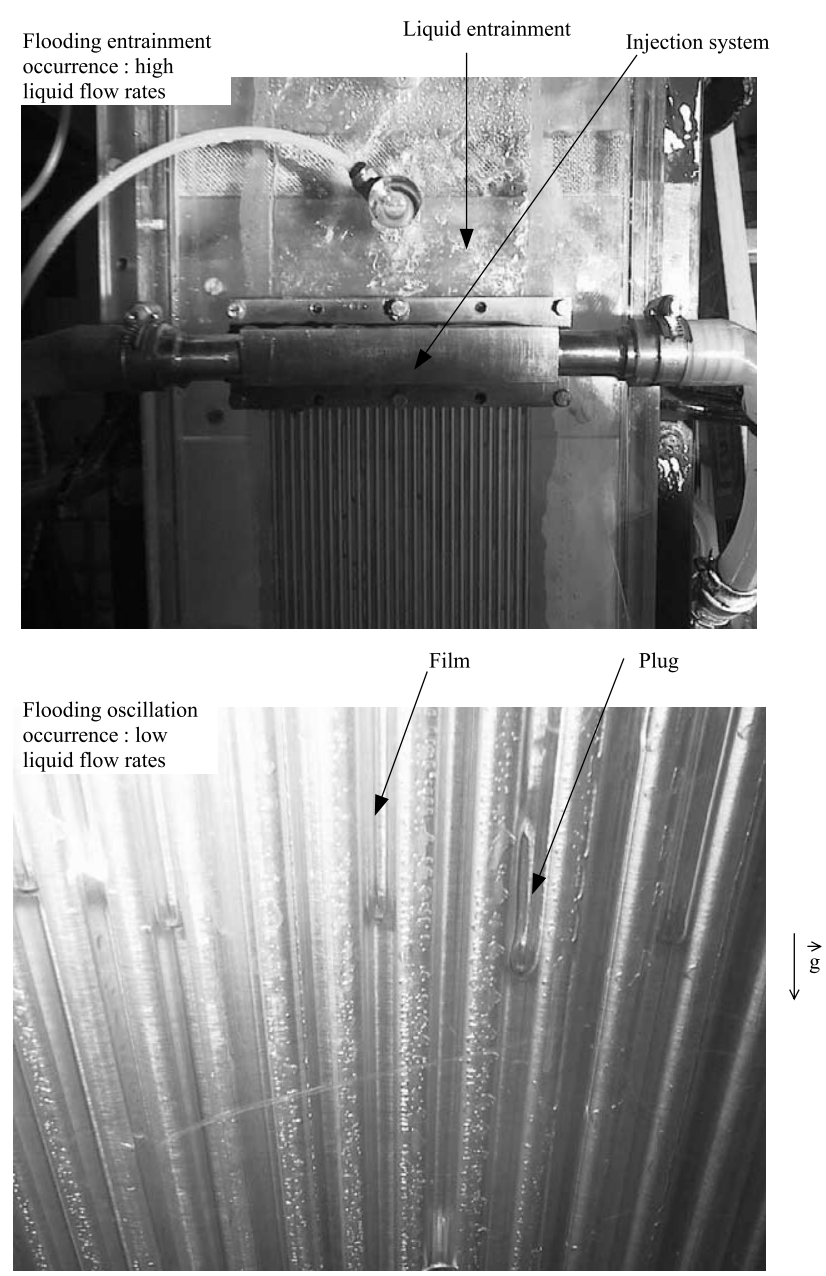

Fig. 7. Flooding occurrence for high and low liquid flow rates. 
sufficient number of channels $(20 \%$ of the test section is flooded).

To summarise, flooding occurs near the injection point for high flow rates whereas it occurs at the lower part of the test section for lower flow rates. The flooding limit in plain fin geometry is considered to be at the point where the flow goes upward in at least three channels $(5-100 \mathrm{l} / \mathrm{h})$, or when liquid is removed above the liquid injection system $(100-300 \mathrm{l} / \mathrm{h})$. The flooding point characteristics cover a large range of air flow rates. As a consequence, the flooding limit reached is assumed to be when no return to a non-flooded state is possible. Fig. 8 is a schematic view of the flow patterns and flooding occurring in the two liquid flow rate ranges.

Dukler and Smith (1977) report five flooding mechanisms depending on liquid flow rates and flow patterns and two of them are observed in the present study. For a thin film thickness, at a given gas velocity, the liquid film is hanging on and the transition leads to cocurrent liquid flow. This phenomenon is called a 'hanging film', which is similar to the two above-described liquid flow rates. Droplets are extracted from the liquid film, which becomes agitated near the injection zone. This is a consequence of the flow pattern (churn flow) predominating for high flow rates.

\subsection{Flooding velocities}

Wallis (1961) defines the following dimensionless superficial velocities,

$J_{i}^{*} \hat{=} \frac{J_{i} \rho_{i}^{1 / 2}}{\left[g l\left(\rho_{\mathrm{L}}-\rho_{\mathrm{G}}\right)\right]^{1 / 2}}, \quad i=(\mathrm{G}, \mathrm{L})$,

where $J_{i}$ is the superficial velocity of the $i$ th phase given by: $J_{i} \hat{=} \dot{M}_{i} / \rho_{i} \mathrm{~S}, \dot{M}_{i}$ is the corresponding mass flow rate, $S$ the channel cross-section area and $l$ the characteristic length. In this study, the latter is assumed to be the hydraulic diameter. $\rho_{\mathrm{G}}$ is determined at the entrance of the test section. Note that $J_{\mathrm{G}}^{*}$ and $J_{\mathrm{L}}^{*}$ are analogous to Froude numbers and represent the ratio of inertial and gravitational forces.

The flooding velocities are often correlated in terms of the dimensionless superficial velocities $J_{\mathrm{G}}^{* 1 / 2}$ and $J_{\mathrm{L}}^{* 1 / 2}$ and the experimental data are plotted in this way, Fig. 9. The flooding points tend to spread out over a relatively large range of the dimensionless superficial air velocity $\left(\Delta J_{\mathrm{G}}^{* 1 / 2}=0.1\right)$ for a defined liquid flow rate $\left(J_{\mathrm{L}}^{* 1 / 2}=0.3\right)$. This is a consequence of the different measurement procedures (increasing or decreasing the air flow rate) and of the definition of the flooding limit (number of flooded channels).

Mishima and Nishihara (1984) and Osakabe and Kawasaki (1989) measured the flooding velocities in rectangular channels. Here, we briefly review their data for narrow rectangular channels. These types of studies have been carried out for nuclear research.

Mishima and Nishihara (1984) used three different single channels with dimensions $5 \times 40,2.4 \times 40$ and $1.5 \times 40 \mathrm{~mm}^{2}$. The channel height was $470 \mathrm{~mm}$. The results and the corresponding correlations are reported in Figs. 11 and 12. The top of the test section has a sharp-edged flange, which is connected to the upper plenum and serves as a water reservoir. Air is introduced by an entrance region, which is $130 \mathrm{~mm}$ long, and a tapered rectangular duct is connected to the bottom of the test section. The test procedure is to fix a gas flow rate and to increase the liquid flow rate until flooding occurs. In this study, flooding is determined by visual observations. It is controlled by the growth of large disturbance waves at the top of the test section. Roll waves grow until their crest touches that on the opposite side of channel and forms a liquid bridge. Flooding occurs only at the top of the test section.

Osakabe and Kawasaki (1989) tested simultaneously three rectangular channels with a cross-section of $10 \times 100$, $5 \times 100$ and $2 \times 100 \mathrm{~mm}^{2}$. Air was supplied to the test section from a lower plenum and discharged through a separator. Water was supplied to an upper plenum and collected at the lower one through the test section. Flooding is determined by measuring the downward water flow rate, but it is not clearly expressed. The data are indicated by stars in Fig. 10. The flooding tendency decreases in the present experimental data indicating that decreasing the number of channels is favourable to the onset of flooding.

Furthermore, the present range of liquid flow rates is larger than in previous investigations cited in the literature since a liquid superficial velocity 0.9 is reached. This is very important since the influence of the liquid flow rate cannot be neglected, especially in narrow channels.

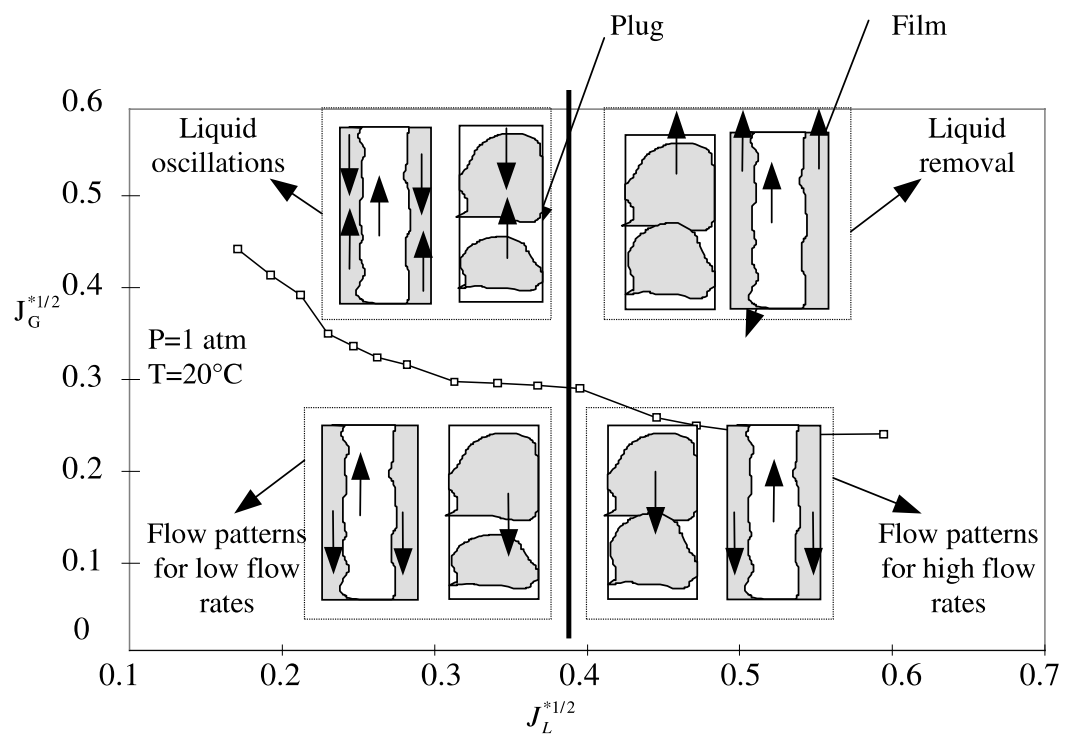

Fig. 8. Flow patterns and flooding occurrence. 


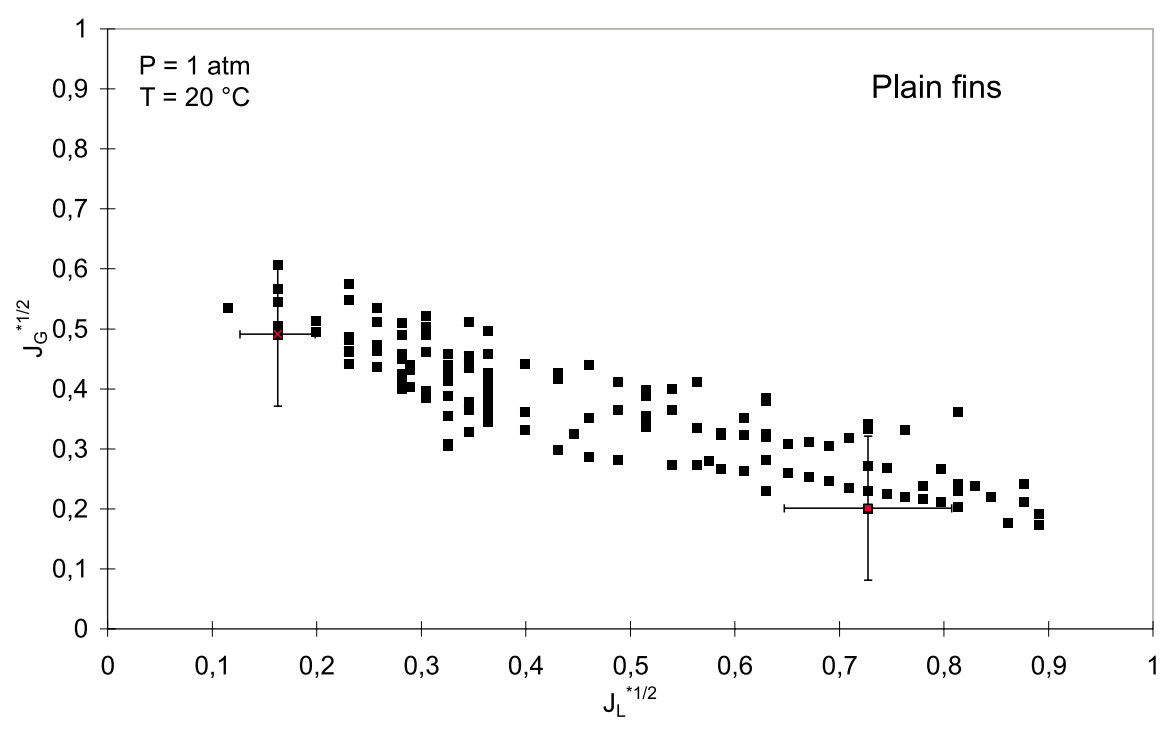

Fig. 9. Flooding superficial velocities for air-water in plain fins.

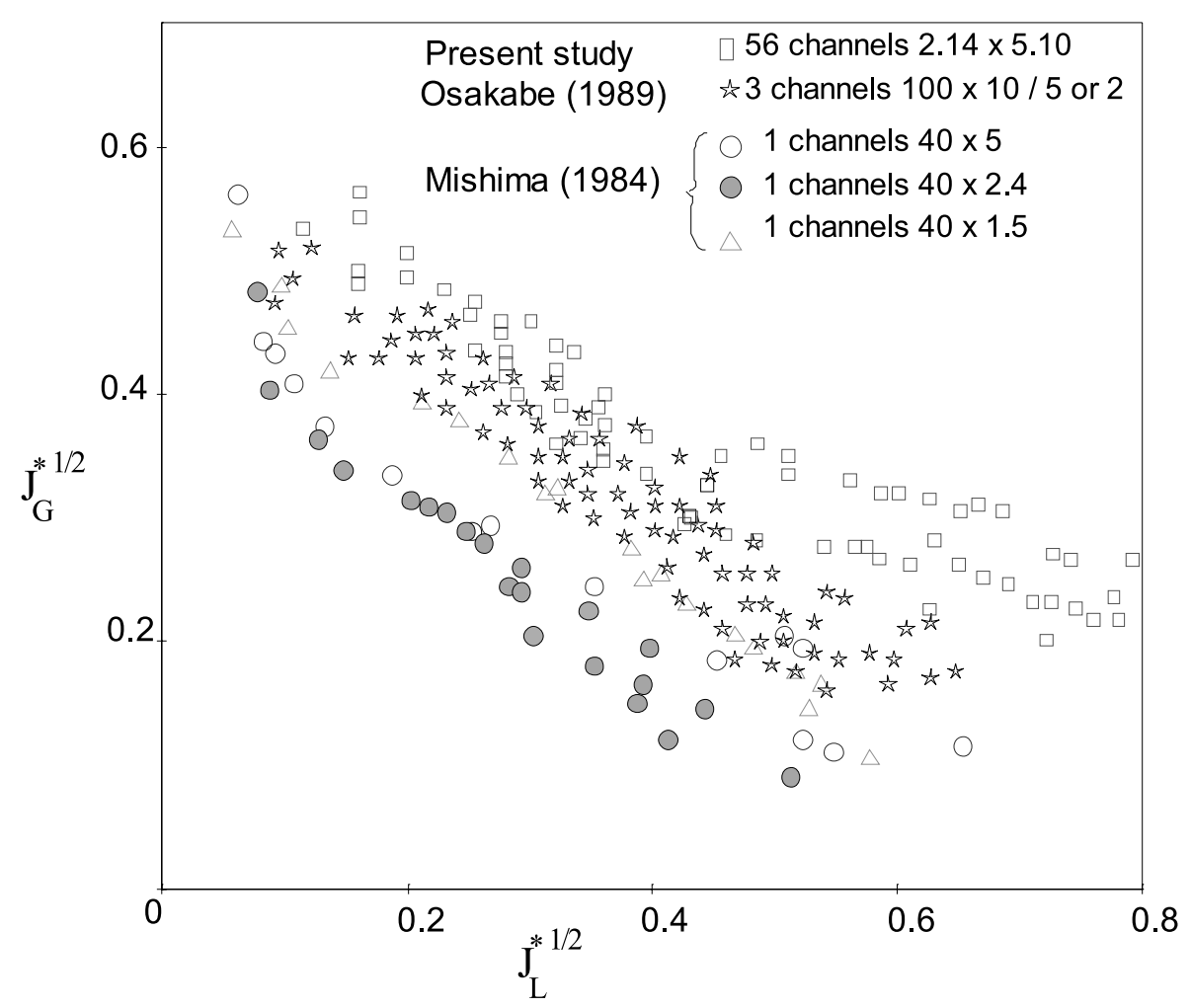

Fig. 10. Experimental data in rectangular channels.

\subsection{Comparison with correlations proposed in literature}

To compare the experimental data with existing correlations, it is wise to recall that empirical relations are usually established in particular experimental configurations. Flooding correlations are simple expressions of entire experimental data sets obtained in specific conditions. Considering the several flooding mechanisms observed, the effect of physical fluid properties, like dynamic viscosity and surface tension and experimental conditions a flooding correlation can be used only within its range of validity.
Essentially two types of flooding correlations have been used throughout the literature. One group correlates the dimensionless gas and liquid velocity under flooding conditions and the other represents the ratio of the gas inertial forces and forces due to gravity acting on capillary waves. The first one, e.g., Wallis (1961), gives the flooding conditions prediction by

$\sqrt{J_{\mathrm{G}}^{*}}+m \sqrt{J_{\mathrm{L}}^{*}}=C$

with $m$ in the range from 0.8 to 1.0 and $C$ in the range from 0.7 to 1.0 , the latter is given by the Kutateladze number and reads 


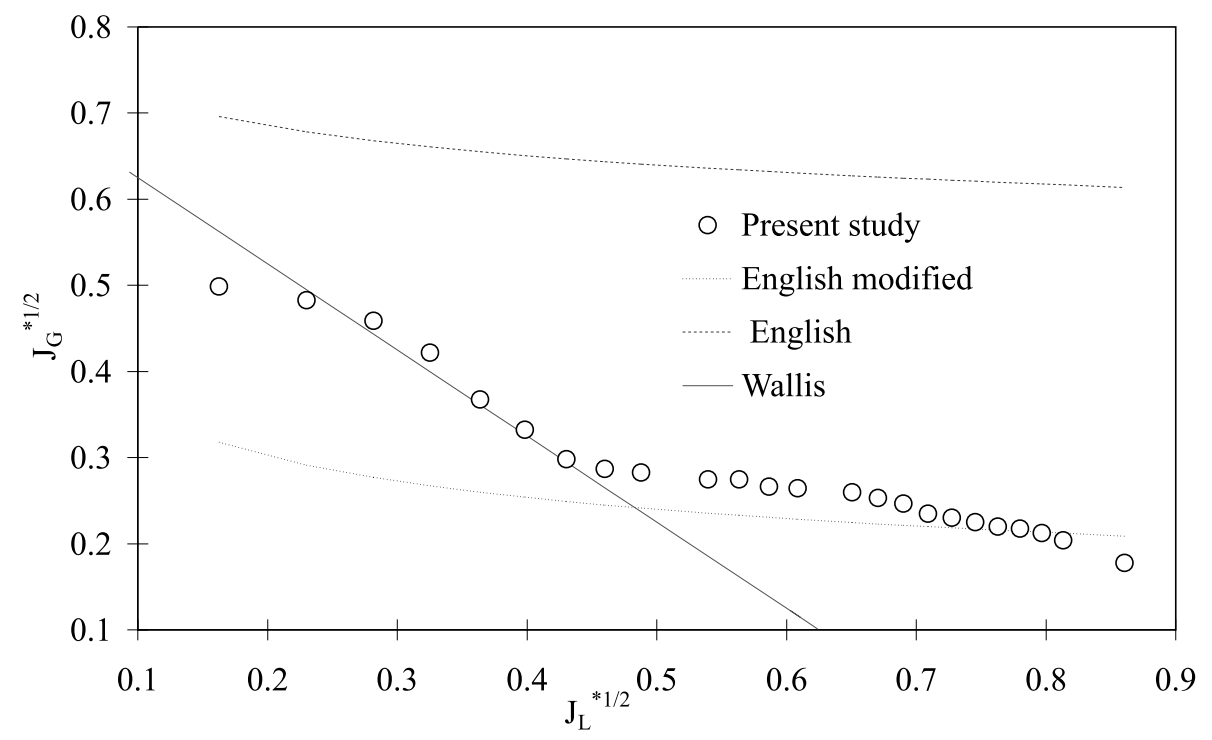

Fig. 11. Comparison of the present study with correlations.

$K u_{i}=\frac{J_{i}^{*} \rho_{i}^{1 / 2}}{\left[g \sigma\left(\rho_{\mathrm{L}}-\rho_{\mathrm{G}}\right)\right]^{1 / 4}}$

with $\left[\sigma /\left(\rho_{\mathrm{L}}-\rho_{\mathrm{G}}\right) g\right]^{1 / 2}$ the characteristic length of the capillary wave. The Kutateladze number can be expressed using the dimensionless superficial velocity and the Bond number

$K u_{i}=J_{i}^{*} B o^{1 / 4}$ and $B o=D_{\mathrm{h}}^{2} \frac{g\left(\rho_{\mathrm{L}}-\rho_{\mathrm{G}}\right)}{\sigma}$.

This study deals either with correlations including physical properties as dynamic viscosity and surface tension or with correlations established for rectangular channels. We select and compute the correlations (7) and (12) for the present data. The five following correlations (7)-(10) are either the more accurate for the present study, i.e., the nearest to the range of validity or the more used in the process industry to predict flooding in reflux condensers or the more used to predict flooding in rectangular channels.

For rectangular channels Wallis (1961) proposed $m=1$ and $C=0.725$ for Eq. (4)

$J_{\mathrm{G}}^{* 1 / 2}+J_{\mathrm{L}}^{* 1 / 2}=0.725$.

Osakabe and Kawasaki (1989) proposed for Eq. (4) $m=0.8$ and $C=0.58$ for three rectangular channels of $10 \times 100$, $5 \times 100$ and $2 \times 100 \mathrm{~mm}^{2}$ tested simultaneously

$J_{\mathrm{G}}^{* 1 / 2}+0.8 J_{\mathrm{L}}^{* 1 / 2}=0.58$.

One rectangular channel with dimensions varying from $5 \times 40$, $2.4 \times 40$ to $1.5 \times 40 \mathrm{~mm}^{2}$, see Mishima and Nishihara (1984)

$J_{\mathrm{G}}^{* 1 / 2}+J_{\mathrm{L}}^{* 1 / 2}=0.6$.

Mc Quillan and Whalley (1985) used the form of Eq. (5)
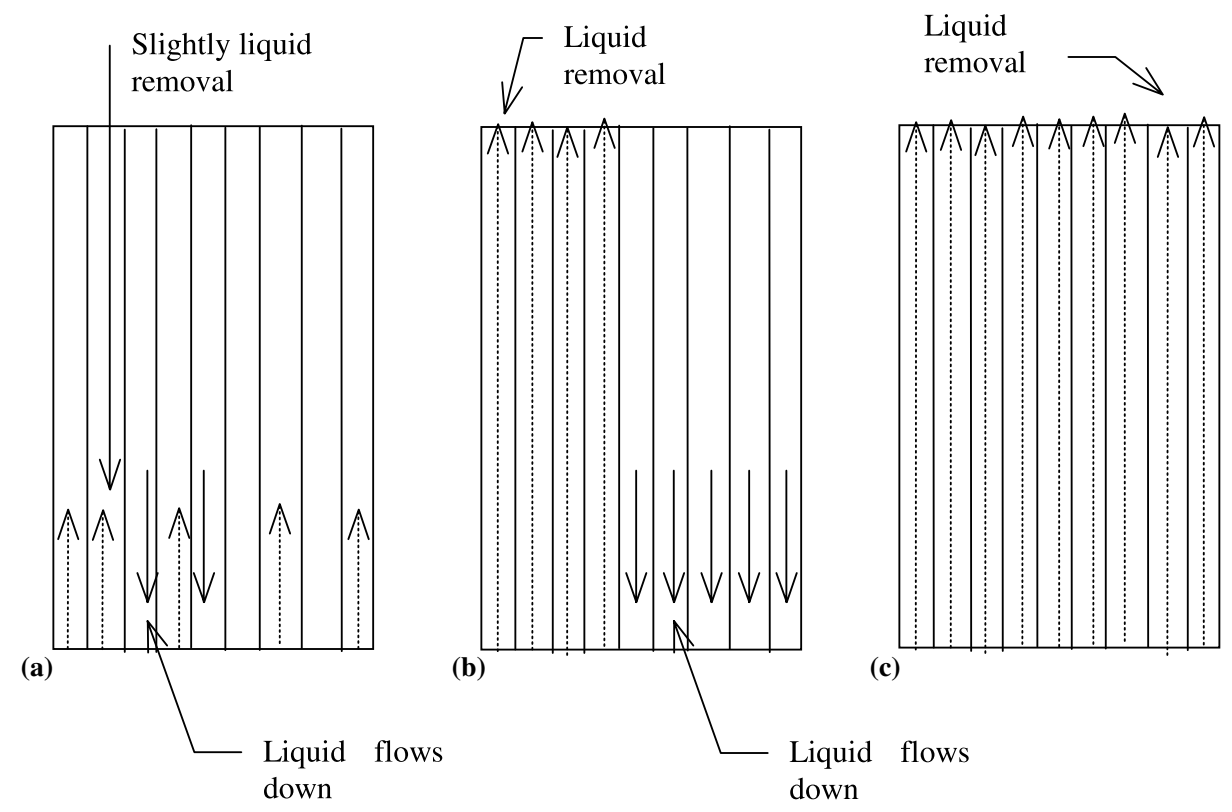

Fig. 12. The onset of flooding in perforated fins, (a) before flooding, (b) flooding, (c) after flooding. 
$K u_{\mathrm{G}}=0.286 B o^{0.26} \mathrm{Fr}^{-0.22}\left(1 \frac{\mu_{\mathrm{L}}}{10^{-3}}\right)^{-0.18}$.

The authors analyse a compilation of a data bank containing 2762 experimental flooding points. As a result, a modified form of the correlation presented by Alekseev et al. (1972) is recommended for the most accurate prediction of flooding conditions. $\mathrm{Fr}$ is the specific Froude number as defined by Mc Quillan and Whalley (1985):

$F r \hat{=} \dot{Q}_{\mathrm{L}}\left(\frac{g\left(\rho_{\mathrm{L}}-\rho_{\mathrm{G}}\right)^{3}}{\sigma^{3}}\right)^{1 / 4}$.

In the process industry, correlation (12) below is used to predict flooding in reflux condensers particularly in reflux condensers with tapered tubes, English et al. (1963)

$J_{\mathrm{G}}=0.286\left\{\frac{D_{\mathrm{h}}^{0.322} \rho_{\mathrm{L}}^{0.419} \sigma^{0.097}}{\rho^{0.462} \mu_{\mathrm{L}}^{0.15} J_{\mathrm{L}}^{0.075}}\right\}$.

However, the Wallis correlation with $m=1$ and $C=0.725$, $J_{\mathrm{G}}^{* 1 / 2}+J_{\mathrm{L}}^{* 1 / 2}=0.725$, seems to be a good approximation for low flow rates (Fig. 11). This result emphasises that gravity forces are far more important than viscous forces in this range. Differently, the English modified correlation, which underlines viscous forces and superficial tension, is more convenient for high flow rates. Moreover, the flow patterns in plain fin channels are not the same in all the channels because they depend on the flow rate studied as we have seen in Section 3.3. Two types of flooding were observed and the results expressing flooding limit in Fig. 11 showed two slopes, so one relationship cannot correlate all the data. The two correlations (7) and (12) modified seem to approximate the present data well. Each correlation corresponds to a specific range of flow rate, the Wallis correlation correlates the data for low flow rates, whereas the modified English correlation is well adapted for higher liquid flow rates.

\section{The onset of flooding with perforated fins}

\subsection{Flooding characteristics}

The usage of reflux condensers with perforated fins is common in the process industry nowadays, because it is supposed that they are more efficient in terms of heat transfer. Otherwise, the efficiency in terms of flooding has not yet been a subject of study to the authors' knowledge. The procedure to obtain the flooding point is different compared to the nonperforated fins. If this procedure has been used to increase the air volume flow rate at fixed liquid volume flow rate the following events were observed:

- no discontinuity in pressure drop, even if the air flow rate is increased to the highest value,

- small oscillations and instability of the liquid flow but no transition to upward flow,

- no liquid removal or flooding point is observed.

The liquid flow rate is fixed at its lowest value of $10 \mathrm{l} / \mathrm{h}$ and the air flow rate is directly increased to its maximum value of $10 \mathrm{~m}^{3} / \mathrm{h}$. The test section is fully flooded in this situation. At this time, the air flow rate is decreased until the flooding limit is reached; this is the procedure to characterise flow reversal so the reversibility of the phenomenon is uncertain. When the air volume flow rate decreases, three configurations are observed (Fig. 12).

The first type occurs when the air volume flow rate is decreased to the lowest value corresponding to the flooding limit. The flooding is partial, one third of the test section height is flooded, and according to the air volume flow rate, a few

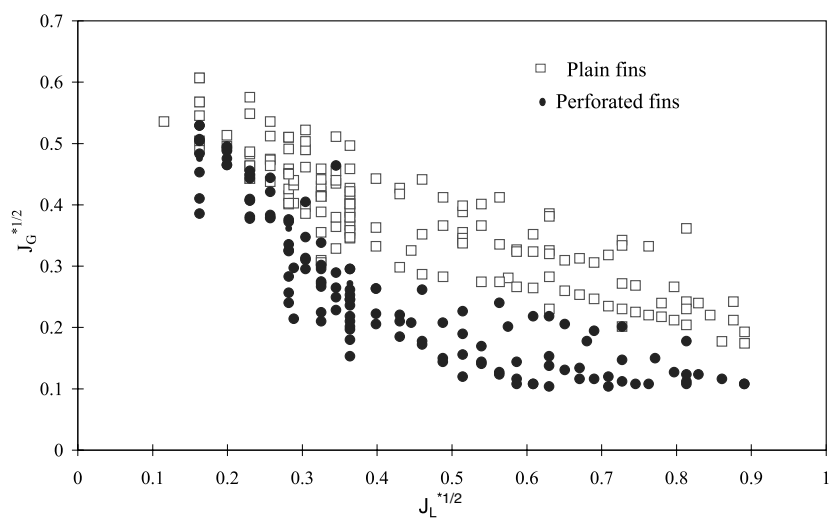

Fig. 13. Flooding occurrence with plain and perforated fins.

channels are flooded (situation (a)). The second type occurs when gas volume flow rate is increased from the former value. All the height of the test section is flooded, but only in some channels (situation (b)). The last type corresponds to a fully flooded test section since all the channels are flooded and the liquid is removed at the top of the test section (situation (c)).

Whereas the first type visually seems to be the onset of flooding, we do not assume this point to be the proper limit. Pressure drop measurements showed no discontinuity at this point. Moreover, if one waits a moment, this flow configuration returns to a typical countercurrent flow. The third type seems to occur after the flooding limit since the liquid is removed in the whole test section. In the second type, some channels are flooded and the pressure drop measurements have a discontinuity at this point. So, the second pattern is assumed to be the definition of flooding in perforated fins.

\subsection{Comparison of the two types of fins}

Fig. 13 shows the superficial velocities at the flooding point for plain and perforated fins. Various types of flooding are represented, particularly the three types presented in the last section.

In the second type of flooding (situation (b) in Fig. 12) the whole plate is not flooded. In the perforated plate, when liquid is removed at the top, liquid tends to go through the perforations. Liquid flows down again in some channels since the liquid is not removed enough by the constant gas volume flow rate. So, this modification in liquid flow distribution has changed the flow patterns and particularly the liquid flow rates in all the channels. Some channels have lower liquid volume flow rates than others at constant gas volume flow rate. This effect can explain the earlier onset of flooding in these channels. So, flooding occurrence in perforated fins is caused by differences in flow distribution in the channels due to lateral perforations.

It seems that the plain fins have a better efficiency than the perforated fins in terms of flooding. However, one can only partially conclude like this since the definitions of the flooding point are different in these two types of geometry. Also the procedure to get flooding is different.

\section{Conclusion}

The present study aims to analyse flooding limit in order to design a compact reflux condenser with a special type of finning defining narrow rectangular channels. Flooding behaviour is studied and the relation between flow patterns and flooding arising is considered. Experimental data are 
compared with previous results of the literature and with empirical correlations.

Visualisation shows that two or three types of flow patterns predominate in the two ranges of flow rate studied, film flow, plug flow and churn flow. So, flooding limit occurs differently according to this range of flow rates. More precisely, the present study shows two types of flooding depending on the two ranges of flow rates, $10-100$ and $100-300 \mathrm{l} / \mathrm{h}$. The first flooding type is characterised by flowing up and down of the liquid and the second type presents entrainment of liquid droplets near the liquid injection point. In terms of superficial velocities, the Wallis relationship, Eq. (1), with $m=1$ and $C=0.725$, correlates well $(2-13 \%)$ with the results for low flow rates.

Perforated fins are studied in the same way to estimate flooding occurrence in such a geometry often used in the process industry. As flooding occurs differently in perforated fins, the procedure to get the flooding limit is different and perforated fins appear to be less efficient in terms of flooding.

The present study tries to determine the flooding limit in a real industrial geometry. Moreover a single channel study is necessary in order to define precisely the flow patterns and transitions in a narrow rectangular channel and to compare with other studies in rectangular channel. A theoretical study will be undertaken to obtain a better understanding of the physical phenomena. Physical properties' influence on viscosity or surface tension has to be studied too.

With the results obtained in adiabatic contercurrent airwater flow, some conclusions for reflux condensation emerge. The present results focus on two particular types of flooding phenomena: the first linked to plugging instability and the second linked to reentrainment. The two types of flooding depend on flow configurations, gas and liquid flow rates. So, we can conclude that flooding at the column base for low condensate flow rate and flooding at the top for high condensation rate will appear in a reflux condenser with similar dimensions. With this assumption, we can design the reflux condenser in terms of dimensions and flow rates.

\section{Acknowledgements}

The authors are grateful to Professor J. M. Delhaye for his valuable suggestions on improving this paper.

\section{References}

Alekseev, V.P., Poberezkin, A.E., Gerasimov, P.V., 1972. Determination of flooding rates in regular packings. Heat Transfer Sov. Res. $4,159-163$.
Barathan, Wallis, G.B., 1983. Air-water countercurrent annular flow. Int. J. Multiphase Flow 9, 349-366.

Bachir, A., 1987. Etude de l'instabilité d'un film liquide ruisselant sur une plaque plane verticale et soumis à un contre-courant de gaz: transition vers l'écoulement cocourant ascendant. Thèse de Doctorat, Institut National Polytechnique de Grenoble.

Celata, G.P., Cumo, M., Farello, G.E., Furrer, M., 1986. Flooding experiments in a rectangular geometry. Heat Technol. 4, 47-57.

Cetinbudaklar, A.G., Jameson, G.J., 1969. The mechanism of flooding in vertical countercurrent two-phase flow. Chem. Eng. Sci. 24, $1669-1680$

Damon, O., 1996. Etude de l'entraînement de gouttelettes à partir de films ruisselant sur des parois lisses ou de forme complexe. Thèse de Doctorat, Université Henri Poincaré Nancy.

Delhaye, J.M., 1981. Two-phase flow patterns. In: Bergles, A.E., Collier, J.G., Delhaye, J.M., Hewitt, G.F., Mayinger, F. (Eds.), Two-Phase Flow and Heat Transfer in the Power and Process Industries. Hemisphere, McGraw Hill, New York, pp. 1-39.

Dukler, A.E., Smith, L., 1977. Two-phase interactions in countercurrent flow studies of the flooding mechanism. U.S. Nuclear Regulatory Agency Report. NUREG/CR-0617.

English, G., Jones, W.T., Spillers, R.C., Orr, V., 1963. Flooding in a vertical updraft partial condenser. Chem. Eng. Prog. 59.

Grolmes, M.A., Lambert, G.A., Fauske, H.K., 1974. Flooding in vertical tubes. Symposium on multiphase flow systems. Glasgow, Paper A4.

Imura, H., Kusuda, H., Funatsu, S., 1977. Flooding velocity in a countercurrent annular two-phase flow. Chem. Eng. Sci. 32, 7987.

Jameson, G.J., Cetinbudaklar, A., 1969. Wave inception by air flow over a liquid film. In: Rhodes, E., Scott, D.S. (Eds.) Proc. Int Symp. on Research in Cocurrent Gas-Liquid Flow, Waterloo, Canada. Plenum Press, New York.

Mc Quillan, K.W., Whalley, P.B., 1985. A comparison between flooding correlations and experimental flooding data for gasliquid flow in vertical circular tubes. Chem. Eng. Sci. 40, 14251440.

Mishima, K., Nishihara, 1984. Flooding velocities for countercurrent air-water flow in thin rectangular channels. Annu. Rep. Res. Reactor Inst. 17, 1-14

Osakabe, M., Kawasaki, Y., 1989. Top flooding in thin rectangular and annular passages. Int. J. Multiphase Flow 15, 747-754.

Shearer, C.J., Davidson, J.F., 1965. The investigation of a standing wave due to gas blowing upwards over a liquid film. J. Fluid Mech. 22.

Wallis, B., 1961. Flooding velocities for air and water in vertical tubes. United Kingdom Atomic Energy Authority Report, AERE-R123.

Webb, D.R., 1996. Future needs and developments in heat exchanger technology, condensation. Heat Exchange Engineering, European Research Meeting, Birmingham, HEE 96/R1. 